\title{
La Menorca talayótica desde el punto de vista genético: la necrópolis de la Cova des Pas
}

\author{
The Minorcan Talayotic Period from a genetic point of view: the Cova des Pas necropolis
}

\author{
Marc Simón $^{\mathrm{a}}$, Núria Armentano ${ }^{\mathrm{a}, \mathrm{b}}$, Cristina Afonso ${ }^{\mathrm{a}, \mathrm{c}}$ y Assumpció Malgosa ${ }^{\mathrm{a}}$
}

\section{RESUMEN}

En el presente artículo se estudian las características genéticas de la población del yacimiento talayótico de la Cova des Pas, que revelan una importante endogamia a nivel de ADN mitocondrial. La comparación con otras series contemporáneas de las Islas Baleares permite hipotetizar la existencia de grupos cerrados, con limitados linajes femeninos y necrópolis de difícil acceso, como esta. Tales comunidades contrastarían con otras más abiertas con un mayor intercambio de linajes femeninos situados en las zonas llanas centrales de Menorca.

\begin{abstract}
Study of the genetic characteristics of the burials at the Talayotic necropolis of Cova des Pas reveals an important level of endogamy at the mitochondrial DNA level. Comparison with other contemporary series from the Balearic Islands permits us to hypothesize the existence of closed groups, with a limited number of female lineages and difficult to access necropoleis, like the present site. The existence of these communities would contrast with other, more open groups located in the central, flat parts of the island with more interchange between female lineages.
\end{abstract}

Palabras claves: Talayótico; Bronce final; ADN mitocondrial; Endogamia; Mediterráneo.
Key words: Talayotic; Late Bronze Age; Mitochondrial DNA; Endogamy; Mediterranean.

\section{INTRODUCCIÓN}

Durante el Bronce final, se produjeron una serie de cambios en las comunidades que habitaron Mallorca y Menorca a nivel sociológico, económico y de relación con otras islas y territorios. Afectaron también a la concepción espacial y territorial, así como al ámbito simbólico, religioso y funerario (Calvo y Guerrero 2011). El resultado fue el desarrollo de una nueva cultura de gran carga simbólica, caracterizada por una arquitectura monumental. En ella destacan las grandes construcciones en forma de torre, llamadas de forma genérica "talayots", que dan nombre a esa cultura (Guerrero et al. 2006a, b). La función principal de los talayots era el dominio del territorio, además de servir como cohesionador social. Estos cambios se inician en el Mediterráneo occidental en la denominada Edad de Hierro (Guerrero et al. 2002), pese a que la cronología y el origen de dicha cultura continúan debatiéndose. Así R. Grosjean (1955) postuló hipótesis ultradifusionis-

\footnotetext{
a Grup de Recerca en Osteobiografia (GROB), Unitat d'Antropologia Biològica. Facultat deBiociències. Universitat Autònoma de Barcelona, Edifici C. Campus de Bellaterra. 08193 Cerdanyola del Vallès. Barcelona. España. Correos e.: marcsimon@hotmail.com http://orcid.org/0000-0002-9569-0416; armentano.nuria@gmail.com http://orcid.org/0000-0003-3306-6797;

Assumpcio.malgosa@uab.cat http://orcid.org/0000-0003-1723-3671.

b Antropòlegs Lab. C/ Rossend Arús, 46 baixos 1ª 08014 Barcelona. España.

c Centro de Investigação em Antropologia e Saúde, Departamento de Ciências da Vida. Universidade de Coimbra. 3000 Coimbra. Portugal.

Recibido: 18-I-2016; aceptado 1-III-2016.
} 
tas para explicar el origen de la cultura torreana en Córcega. G. Rosselló (1979) las adaptó y propuso como iniciadores de la cultura talayótica a las gentes llamadas Pueblos del Mar (Sandars 1978) o algún otro pueblo desplazado por ellos. Estas "oleadas" de conquistadores o emigrantes habrían sido rechazadas de algunas zonas del Mediterráneo Oriental a finales del II milenio. En su expansión hacia Occidente ocuparían sucesivamente las islas que fueron encontrando a su paso: Córcega, Cerdeña, Menorca y Mallorca. Sin embargo, algunos autores defienden la posibilidad de una evolución más autóctona (Salvà 1999) y retrotraen el origen de la cultura talayótica al siglo XVII a. C. (muy a finales) o, en todo caso, al siglo XVI a. C. (Waldren y Van Strydonck 1992; ${ }^{\text {; }}$ Juan y Plantalamor 1997; Pons 1999). Esta fecha es anterior a los primeros Pueblos del Mar documentados hacia el siglo XIV a. C., aunque hasta finales del siglo XIII a. C. y principios del XII a. C. no se dieran los conflictos que originaron su supuesta difusión hacia Occidente (Arribas 1988; Cardell et al. 1994; Salvà 1999). Otros estudiosos, que también defienden causas últimas endógenas de los orígenes, gestadas algún tiempo antes en el seno de las comunidades isleñas del periodo del Bronce Naviforme (Guerrero et al. 2002), ponen en duda la idoneidad de las muestras que se han usado tradicionalmente como referencia para la datación del inicio de la cultura talayótica (por ejemplo, en Rosselló y Waldren 1973; Rosselló 1979; Fernández-Miranda y Waldren 1979). Según estudios posteriores (Rosselló 1987; Mestres y Nicolás 1999) las dataciones ligadas de forma incontrovertible a la construcción de elementos turriformes menorquines no superan el año $1000 \mathrm{a}$. C. (Guerrero et al. 2002). En los últimos tiempos parece estar llegándose a un consenso general que sitúa su origen en el tránsito del II al I milenio, entre el 1100 y el 850 a. C. (Calvo y Guerrero 2011) pero el debate de la cronología sigue abierto.

Es bien conocido que las comunidades talayóticas hasta el 800-700 a. C. siguieron utilizando las antiguas necrópolis originarias del Bronce Final: cuevas naturales con muro de cierre ciclópeo en las estribaciones de los barrancos o navetas funerarias en las zonas más llanas. Igualmente hay noveda-

\footnotetext{
1 Juan, G. 1995: La Naveta de Cala Blanca al Bronze Menorquí. Tesis doctoral inédita. Universitat de Barcelona. Barcelona.
}

des como el enterramiento en cal o las necrópolis de hipogeos de planta sencilla en Menorca. Esta gran diversidad de estrategias funerarias corrobora la enorme complejidad de las primeras fases (900-800 a. C.) de la cultura talayótica (Calvo y Guerrero 2011). En este horizonte cronológico se conocen en Menorca complejos funerarios como los monumentos circulares de Son Olivaret (Plantalamor et al. 2008), navetas como la de Rafal Rubí $^{2}$ en las zonas centrales de la isla, o las cuevas excavadas en los acantilados de calas y barrancos como la de Calascoves (Alaior). Las cuevas más antiguas tienen planta circular u ovalada, son de pequeñas dimensiones y están en sitios elevados de difícil acceso como la Cova des Càrritx (Lull et al. 1999a), la Cova del Mussol (Lull et al. 1999b) o la Cova des Morts de Mongofre Nou (Bergadà y Nicolàs 2005). En este contexto, se sitúa la Cova des Pas, uno de los yacimientos funerarios más importantes de Menorca.

\section{DESCRIPCIÓN DE LOS RESTOS ENCONTRADOS}

La Cova des Pas es una cueva kárstica situada al sur de la isla de Menorca, en la finca de Son Mercer de Baix, en el término municipal de Ferreries (Fig.1A, B). Se abre en la pared de un acantilado en la zona sureste del barranco de Trebalúger (3957'50" E, $80 \mathrm{~m} \mathrm{s.} \mathrm{n.} \mathrm{m.),} \mathrm{a} \mathrm{unos} 15$ $m$ por encima del suelo del cañón.

Fue descubierta en la primavera de 2005 por unos espeleólogos de la zona, que inmediatamente notificaron el descubrimiento al Departamento de Cultura del Consell Insular de Menorca. En septiembre del mismo año empezaba la excavación arqueológica con la formación de un equipo interdisciplinar de la Universitat de les Illes Balears (UIB), Universitat de Barcelona (UB) y Universitat Autònoma de Barcelona (UAB). Integraba historiadores, arqueólogos, antropólogos, restauradores, médicos y diferentes especialistas que trabajaron en el yacimiento durante los cinco meses que duró la intervención (Fullola et al. 2007).

\footnotetext{
${ }^{2}$ Fadrique, T. y Malgosa, A. "Aproximacions antropològiques a una població prototalaiòtica menorquina. Estudi de les restes humanes procedents de la naveta septentrional de Rafal Rubí (Alaior, Menorca)". Revista de Menorca (en prensa).
}

Trab. Prehist., 73, N. ${ }^{\circ}$ 2, julio-diciembre 2016, pp. 335-351, ISSN: 0082-5638

doi: $10.3989 /$ tp. 2016.12178 


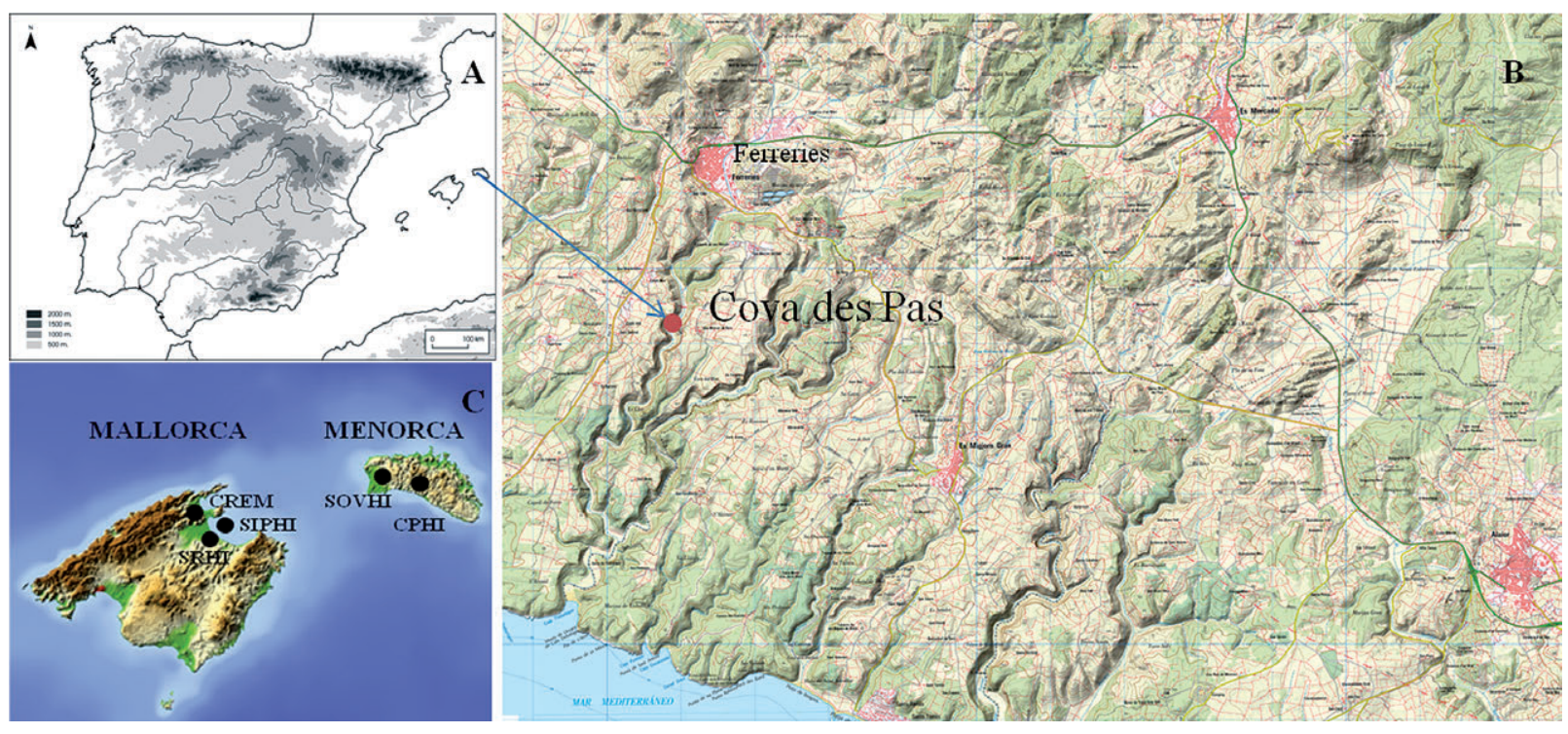

Fig. 1. Localización de la necrópolis de la Cova des Pas en las Islas Baleares (escala 1:1.000.000) (A) señalada de forma precisa (B) en un mapa 1:25.000 de la zona sur de Menorca. Coordenadas UTM: ETRS89; Zona 31, Hemisferio Norte; última edición: 2/7/2001. Coordenadas geográficas: 3957' 50” E, $80 \mathrm{msm}$. (C) Situación de las 5 series antiguas de individuos estudiadas: Cova des Pas (CPHI), Son Olivaret (SOVHI), Son Real (SRHI), S'Illot des Porros (SPHI) y Can Reiners (CREM). Fuente: Base Cartográfica Nacional, Ministerio de Fomento, Gobierno de España (consulta 19-II-16).

La cueva tiene una forma irregular. Mide unos $6,5 \mathrm{~m}$ de profundidad, $4,5 \mathrm{~m}$ de anchura y 1,70 $\mathrm{m}$ de altura. En algunos puntos de la entrada se observan retoques antrópicos que indican su probable modificación (Fullola et al. 2008). Una parte de la visera original que cerraría parcialmente la cueva debió desprenderse, debilitada por la erosión, en un momento indeterminado pero posterior al uso sepulcral.

El yacimiento de la Cova des Pas resultaba adecuado para incluirse, junto a otros de la Edad de Hierro en las Baleares (Fig. 1C), en un estudio que incorporase el análisis genético a la descripción de sus características, debido a su importante volumen de restos esqueléticos que ocupaban la totalidad de su superficie (Fig. 2). Dichos restos mantenían una disposición anatómica articulada pero en una posición de flexión muy forzada con una importante superposición e imbricación. Corresponden a un número mínimo de 66 individuos: infantiles, juveniles y adultos, sin perinatales, ni seniles (Armentano et al. 2010). $\mathrm{Su}$ utilización como necrópolis abarca unos 100 años de las últimas etapas de la Prehistoria de la isla de Menorca (900-800 cal a. C., Van Strydonck et al. 2010).

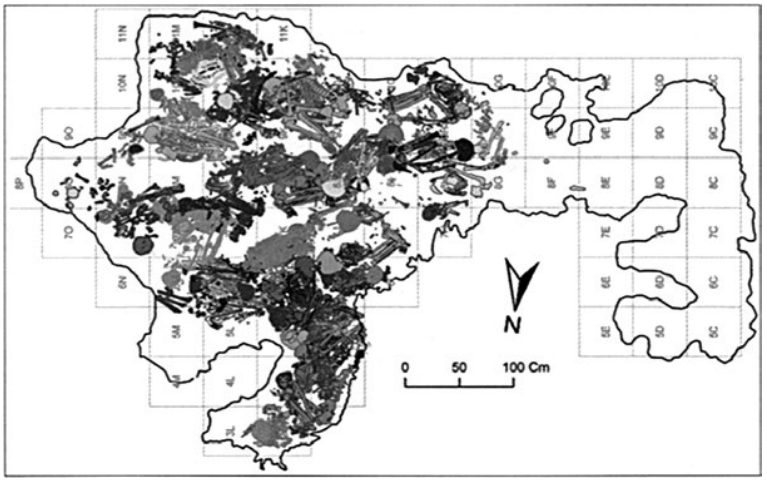

Fig. 2. Planimetría de la Cova des Pas (Menorca) y representación de los individuos encontrados.

En estrecha vinculación con los huesos se recuperó una relevante variedad de materiales de origen biológico, con una preservación excepcional para un yacimiento arqueológico de esta cronología: restos de maderas, pieles de animales, cuerdas y otras fibras vegetales, así como elementos de origen humano de naturaleza no ósea como cabellos, piel, fibras musculares y órganos internos. 
El ambiente, las características geomorfológicas de la cavidad y el propio ritual funerario podrían haber contribuido a su preservación. Los factores físico-químicos, geológicos y ambientales sugieren un predominio del ambiente seco estable en la cueva donde se encontraron minerales altamente solubles como el nitrato de sodio y el yeso. La estructura microcristalina del yeso indica un origen diagenético, considerado resultado de la oxidación del azufre orgánico de los cuerpos enterrados (Bergadà et al. 2015). Estos minerales absorberían la baja humedad presente en los sedimentos e inducirían la conservación natural de los cuerpos mediante la inhibición parcial de la actividad bacteriana (Cabanes y Albert 2011).

El ritual funerario, por su parte, implicaba el enterramiento de los individuos en posición flexionada muy forzada, envueltos con pieles y atados con cuerdas formando fardos funerarios (Armentano et al. 2012). Así fueron transportados en literas hasta la cueva, donde se han encontrado restos de diversas parihuelas. Bajo algunos cuerpos se hallaron depósitos de pequeñas ramas y hojas en forma de lecho mortuorio ${ }^{3}$, lo que confirma la complejidad de la práctica sepulcral, y el estudio histológico y químico de los tejidos humanos conservados muestra que el mecanismo de preservación fue, en un primer momento, la formación de adipocera (Prats-Muñoz et al. 2013) favorecida por la acumulación de cuerpos. En conjunto, las evidencias indican que el tipo de ritual funerario y las condiciones ambientales favorecieron esta conservación.

Este estudio pretende una amplia caracterización de la población inhumada en La Cova des Pas. Busca concretar la composición de la población confirmando el sexo de los individuos subadultos mediante el análisis genético, interpretar las relaciones intra e interpoblacionales mediante la determinación de los haplogrupos mitocondriales y conocer el origen de la población comparando los resultados obtenidos con poblaciones actuales $\mathrm{y}$ antiguas de las Islas Baleares.

\footnotetext{
${ }^{3}$ Servera, B.; Riera, S.; Miras, Y.; Picornell, L.; Armentano, N.; Allué, E., Esteve, X. y Boi, M. 2008: "Plants and death in the Late Bronze Age of Minorca Island: plant uses, funerary offerings and symbolism in the "Cova des Pas" collective burial cave". Terra Nostra 2008/2: 254-255. IPC-XII/IOPC-VIII. Abstract Volume. Bonn, Germany. ISSN: 0946-8978.
}

\section{MATERIAL Y MÉTODOS}

Se estudiaron muestras procedentes de 50 individuos enterrados en la Cova des Pas. Las muestras fueron extraídas in situ en cuanto la pieza quedaba expuesta, usando material de protección de un solo uso (mascarilla y guantes). Cuando fue posible, se escogieron piezas dentales sin ningún tipo de fractura que pudiesen ser asignadas sin duda a un individuo determinado. Cuando no lo fue, se tomó una pieza del esqueleto postcraneal. Debido a la diferente estructura de huesos y dientes, el protocolo de descontaminación fue ligeramente distinto en ambos casos. Los dientes se sumergieron en lejía al 5\% durante 5 min en un tubo Falcon previamente esterilizado con luz ultravioleta (UV en adelante) durante $30 \mathrm{~min}$. Dicho tubo se agitó de forma intermitente con la intención de eliminar los restos de suciedad y minimizar el ADN contaminante. Posteriormente, cada una de sus caras fue expuesta durante $15 \mathrm{~min}$ a luz UV y se llevó a cabo la extracción en series de 4 o 5 muestras y un blanco de control. Cada pieza fue cortada por su límite amelocementario usando material odontológico, y se extrajeron 0,5 $\mathrm{g}$ de polvo procedente de la dentina de la cavidad pulpar usando un micromotor de alta velocidad al que se le acopló una fresa de diamante (Solórzano 2006; Díaz 2009).

La estructura porosa de los huesos evitó el uso de lejía y la exposición a luz UV que podrían afectar la integridad del material genético y disminuir la eficiencia de los resultados. Cada hueso fue cortado con una fresa serrada en la parte medial de la diáfisis, se eliminó la capa de hueso esponjoso con una fresa en punta, y se extrajo aproximadamente $1 \mathrm{~g}$ de polvo de tejido compacto interno del canal medular. La cantidad de polvo extraída fue mayor en huesos ya que la eficiencia en la extracción es menor en las piezas óseas (Schultes et al. 2000; Díaz 2009).

\subsection{Estudios moleculares}

Se utilizaron dos métodos de extracción del ADN a fin de maximizar el éxito en la recuperación del material genético. Uno de los métodos está basado en la metodología clásica del fenolcloroformo, mientras que el otro utilizó un kit

Trab. Prehist., 73, N. ${ }^{\circ}$ 2, julio-diciembre 2016, pp. 335-351, ISSN: 0082-5638

doi: $10.3989 /$ tp. 2016.12178 
comercial de Qiagen específico para muestras degradadas. El método de extracción del fenolcloroformo modificado (Malgosa et al. 2005) consistió en la incubación del polvo de dentina o hueso durante toda la noche en $5 \mathrm{ml}$ de buffer de extracción (TrisHCl 1M [pH 8,0-8,5], SDS10\%, EDTA $0,5 \mathrm{M}$ y agua estéril desionizada) y $50 \mathrm{ul}$ de proteinasa $\mathrm{K}$ a $0,01 \mathrm{~g} / \mathrm{ml}$. Después de la incubación, el ADN fue extraído con el método del fenol-cloroformo y la fase acuosa fue concentrada usando las columnas de filtración Centricon-30 (Millipore) eluyendo un volumen final de $30 \mathrm{ul}$. No obstante, el porcentaje de éxito obtenido fue escaso. Por ello, se ensayó con un kit comercial especialmente preparado para muestras forenses: el QIAamp DNA Investigator (Qiagen), con el cual los resultados mejoraron notablemente (Simón et al. 2012). Siguiendo esta nueva metodología, las muestras se incubaron con EDTA $0,5 \mathrm{M}$ en agitación constante durante toda la noche a $37^{\circ} \mathrm{C}$. Al día siguiente, se prosiguió con la extracción tal y como especifica el protocolo del kit. Cuando no se obtuvieron resultados tras 3 reacciones de amplificación, se realizó un paso extra de purificación para tratar de eliminar el remanente de inhibidores que pudieran quedar. Las muestras que seguían proporcionando resultados negativos se descartaron. Globalmente, este segundo protocolo proporcionó un mayor porcentaje de éxito que el del fenol-cloroformo (Simón et al. 2012).

Debido a que suele haber varios centenares de copias de ADN mitocondrial (ADNmt en adelante) por cada copia de ADN nuclear (Poinar et al. 2006; Kuch et al. 2007), y a que parece conservarse mejor en los procesos de diagénesis (Schwarz et al. 2009), se ha usado esta molécula en este trabajo como principal fuente de información. Entre sus ventajas se incluyen una herencia exclusivamente materna sin recombinación y una alta tasa de mutación, por lo que se puede seguir su huella en períodos de tiempo relativamente cortos (Ramakrishnan y Hadly 2009).

Para su análisis se tuvo en cuenta tanto la secuencia de la primera región hipervariable I del D-loop (RHVI en adelante) a fin de determinar el haplotipo como los polimorfismos de restricción (RFLPs en adelante) de su zona codificante para determinar el haplogrupo, al igual que se había realizado con el resto de poblaciones antiguas usadas en este estudio (Díaz 2009; Simón y Malgosa 2014). En primer lugar se amplificó un fragmento de 231 pares de bases ( $\mathrm{pb}$ en adelante) de la RHVI entre las posiciones 16210 y 16400 . En los casos en los que no se obtuvo amplificación, se analizaron 2 fragmentos más pequeños solapantes, de 129 y 150 pb, que abarcan esta región (Tab. 1A). Para amplificar las fragmentos de la región codificante que contienen las posiciones que definen los haplogrupos y llevar a cabo la restricción (Torroni et al. 1996; Richards et al. 2000), se usaron pares de primers para amplificar fragmentos de aproximadamente $120 \mathrm{pb}$ (Tab. 1B) ${ }^{4}$.

Las reacciones de PCR se llevaron a cabo en un volumen final de 50 ul usando la ADN polimerasa AmpliTaq Gold® (Applied Biosystems). La amplificación consistió en un primer paso de desnaturalización de 10 min a $94^{\circ} \mathrm{C}$, seguido de 39 ciclos de amplificación $\left(50 \mathrm{~s}\right.$ a $94^{\circ} \mathrm{C}, 1 \mathrm{~min}$ a la temperatura adecuada de annealing dependiendo de la región a amplificar y una fase de elongación de $1 \mathrm{~min}$ a $72^{\circ} \mathrm{C}$ ) y un paso final de elongación de 5 min a $72^{\circ} \mathrm{C}$, o de 10 min cuando la región amplificada iba a ser clonada. La purificación de las secuencias amplificadas se realizó mediante el JetQuick PCR Purification kit (Genomed). Los productos amplificados fueron visualizados con bromuro de etidio en un gel de agarosa al 3\%. Las reacciones de secuenciación se llevaron a cabo utilizando el kit BigDye Terminator v.3.1 (Applied Biosystems), siguiendo las instrucciones del fabricante, y se analizaron en un secuenciador ABI 3130XL (Applied Biosystems). El proceso de clonación se llevó a cabo usando el TOPO TA Cloning Kit (Invitrogen).

Cuando fue posible, las muestras se asignaron a haplogrupos usando la información combinada de la RHVI y los polimorfismos de la región codificante, siguiendo la clasificación filogenética actualizada que iniciaron van Oven y Kayser (2009).

Para la determinación del sexo se analizó el polimorfismo de longitud en el primer intrón del gen que codifica para la amelogenina (Nakahori et al. 1991). El tamaño del gen en ambos cromosomas sexuales difiere a causa de la deleción de $6 \mathrm{pb}$ en el cromosoma X. La diferencia en la longitud del fragmento se detectó en un gel de Nusieve al $3 \%$ a $120 \mathrm{~V}$ durante $30 \mathrm{~min}$. Existía la posibilidad de que, en algunos casos, sólo amplificase la banda de amelogenina de un tamaño de $106 \mathrm{pb}$

${ }^{4}$ Díaz, N. 2005: Caracterización genética de la serie talayótica de S'Illot des Porros-Son real, Mallorca. Tesis de máster inédita, Universitat Autònoma de Barcelona. Bellaterra. 


\begin{tabular}{|c|c|c|c|c|c|}
\hline $\begin{array}{c}\text { A Fragmento } \\
\text { RHVI }\end{array}$ & Primers & Sitio de restricción & $\begin{array}{c}\text { B } \\
\text { Primers }\end{array}$ & Coordenadas & Secuencias de los primers \\
\hline & & -7025 Alu I & L6968/H7052 & 6949-6968 & 5'-CCGTAGGTGGCCTGACTGGC-3' \\
\hline & & & $(123 \mathrm{pb})$ & $7071-7052$ & 5'-TGATGGCAAATACAGCTCCT-3' \\
\hline & L-16209 : 5'-CCCCATGCTTACAAGCAAGT-3' & & $\begin{array}{c}\text { (Francalacci } \\
\text { comunicación } \\
\text { personal) }\end{array}$ & & \\
\hline \multirow{5}{*}{$\begin{array}{c}\text { Fragmento } 1 \\
(231 \mathrm{pb})\end{array}$} & (Montiel et al. 2001) & & & & \\
\hline & H -16401 : 5'-TGATTTCACGGAGGATGGTG-3' & -9052 Hae II & L9020/H9082 & $9000-9020$ & 5'-ACGCCTAACCGCTAACATTAC-3 \\
\hline & (Vigilant et al. 1991) & & $(104 \mathrm{pb})$ & $9103-9082$ & 5'AGATGATAAGTGTAGAGGGAAG-3' \\
\hline & & & (Montiel 2001) & & \\
\hline & L-16209 : 5'-CCCCATGCTTACAAGCAAGT-3' & & & & \\
\hline \multirow[t]{4}{*}{$\begin{array}{c}\text { Fragmento } 2 \\
(150 \mathrm{pb})\end{array}$} & (Montiel et al. 2001) & +11719 Hae III ${ }^{1}$ & L11650/H11771 & $11650-11669$ & 5'-AGTAACAGCCATTCTCATCC-3' \\
\hline & H-16339 : 5'-GTGCTATGTACGGTAAATGG-3' & & $(122 \mathrm{pb})$ & $11771-11752$ & 5'-GAGTGCGTTCGTAGTTTGAG-3' \\
\hline & (Díaz 2009) & & (Díaz 2009) & & \\
\hline & L-16313 : 5'-CACCCTTAACAGTACATAGTAC-3' & +12308 Hinf I & L12237/H12309 & $12216-12237$ & 5'-CACAAGAACTGCTAACTCATGC-3' \\
\hline \multirow[t]{8}{*}{$\begin{array}{c}\text { Fragmento } 3 \\
\text { (129pb) }\end{array}$} & (Montiel et al. 2001) & & $(123 \mathrm{pb})$ & $12338-12309$ & 5'-ATTACTTTTATTTGGAGTTGCACCAAGATT-3' \\
\hline & H -16401 : 5'-TGATTTCACGGAGGATGGTG-3' & & (Izagirre 1998) & & \\
\hline & & -8994 Hae III & L8927/H9014 & $8908-8927$ & 5'-TTCTTACCACAAGGCACACC-3' \\
\hline & & & $(125 \mathrm{pb})$ & $9032-9014$ & 5'AGGTGGCCTGCAGTAATGT-3' \\
\hline & & & (Montiel 2001) & & \\
\hline & & +14465 Acc I & L14399/H14533 & $14399-14417$ & 5'-ACACTCACCAAGACCTCAA-3' \\
\hline & & & $(135 \mathrm{pb})$ & $14533-14514$ & 5'-GGGAGGTTATATGGGTTTAA-3' \\
\hline & & & (Díaz 2005) & & \\
\hline
\end{tabular}

${ }^{1}$ En este caso el resultado se obtuvo secuenciando la zona amplificada y observando la presencia o ausencia de la diana de restricción.

Tab. 1. Muestras procedentes de 50 individuos enterrados en la Cova des Pas: A. Primers usados para secuenciar la primera región hipervariable del DNAmt (RHVI); B. Primers de la región codificante y sitios de restricción. pb pares de bases de la primera región hipervariable I del D-loop.

correspondiente al cromosoma $\mathrm{X}$, pudiendo ser un falso positivo para el sexo femenino. Por ello, a modo de control, se realizó una amplificación para cada individuo para un fragmento de $93 \mathrm{pb}$ del gen SRY del cromosoma Y (Santos et al. 1998) (Tab. 2). Dicho fragmento amplifica exclusivamente en los individuos masculinos.
El tratamiento estadístico de los datos en lo concerniente a haplogrupos y haplotipos se hizo mediante el programa Arlequin v3.1 (Excoffier et al. 2005). Además de comprobar la presencia o ausencia de diferencias significativas entre las poblaciones en estudio, se efectuó un escalamiento multidimensional para el análisis de secuencias 


\begin{tabular}{|c|c|}
\hline $\begin{array}{c}\text { Primers Amelogenina } \\
(106 \text { y 112 pb) } \\
\text { (Nakahori } \text { et al. } 1991)\end{array}$ & $\begin{array}{c}\text { AMEF: } \\
\text { ATCAGAGCTTAAACTGGGAAGCTG-3' } \\
\text { AMER: 5'- }\end{array}$ \\
\hline $\begin{array}{c}\text { Primers SRY (93 pb) } \\
\text { (Santos } \text { et al. } 1998)\end{array}$ & 5'-ATAAGTATCGACCTCGTCGGAA-3' \\
& S'-GCACTTCGCTGCAGAGTACCGA-3' \\
\hline
\end{tabular}

Tab. 2. Primers de amelogenina y del gen SRY del cromosoma $\mathrm{Y}$ utilizados para la determinación de sexo en las muestras procedentes de 50 individuos enterrados en la Cova des Pas.

usando un fragmento de $156 \mathrm{pb}$ de la RHVI, que abarcaba las posiciones 16210 a 16365 , a partir de los valores transformados de FST en la matriz de Slatkin (1995). Finalmente, para el análisis de correspondencias de haplogrupos se manejó el paquete estadístico SPSS (v.15.0).

\subsection{Necrópolis baleares utilizadas en la comparación y análisis estadísticos}

La población inhumada en la Cova des Pas se contextualizó geográfica e históricamente. Para ello, se compararon los resultados obtenidos con los de otras poblaciones antiguas (Fig. 1C) y actuales de las Islas Baleares (Tab. 3). Las primeras contaban con el mismo tipo de análisis en lo referente a la secuenciación de un fragmento de la RHVI (posiciones 16210 a 16400 para determinar el haplotipo y hasta la 16365 para análisis estadísticos) y a la determinación de su haplogrupo mediante el análisis con RFLPs (Díaz 2009; Simón y Malgosa 2014). El estudio previo sobre las segundas (Picornell et al. 2005) consideró toda la RHVI (posiciones 15997 a 16400) pero sólo utilizó el RFLP determinante del haplogrupo $\mathrm{H}$ (-7025 AluI). Por ello, los análisis estadísticos que se presentan tienen en cuenta la región de dichas secuencias usada para las poblaciones antiguas, mientras que el haplogrupo más probable de los individuos no $\mathrm{H}$ se asignó mediante el programa HaploGrep (van Oven y Kayser 2009; KlossBrandstäter et al. 2010). Además, se incluyen la tabla 4 con los haplogrupos, haplotipos y el sexo de los investigadores que tuvieron contacto con las muestras analizadas aquí.

\begin{tabular}{|c|c|c|c|c|c|c|}
\hline Pobl. & Abrev. ${ }^{1}$ & $\begin{array}{l}{ }^{2} \mathbf{N} \\
\text { hap }\end{array}$ & $\begin{array}{l}{ }^{3} \mathrm{~N} \\
\sec \end{array}$ & Periodo & Región & Referen. \\
\hline \multicolumn{7}{|l|}{ Ant. } \\
\hline $\begin{array}{l}\text { Cova } \\
\text { des Pas }\end{array}$ & $\mathrm{CPHI}$ & 20 & 17 & $\begin{array}{l}\text { Edad de } \\
\text { Bronce- } \\
\text { Hierro }\end{array}$ & $\begin{array}{l}\text { Menorca, } \\
\text { Islas Bal. }^{4}\end{array}$ & $\begin{array}{l}\text { Presente } \\
\text { estudio }\end{array}$ \\
\hline $\begin{array}{l}\text { Son } \\
\text { Olivaret }\end{array}$ & SOVHI & 22 & 15 & $\begin{array}{l}\text { Edad de } \\
\text { Hierro }\end{array}$ & $\begin{array}{l}\text { Menorca, } \\
\text { Islas Bal. }\end{array}$ & $\begin{array}{l}\text { Simón y } \\
\text { Malgosa } \\
2014\end{array}$ \\
\hline $\begin{array}{l}\text { Son } \\
\text { Real }\end{array}$ & SRHI & 37 & 22 & $\begin{array}{l}\text { Edad de } \\
\text { Hierro }\end{array}$ & $\begin{array}{l}\text { Mallorca, } \\
\text { Islas Bal. }\end{array}$ & Díaz 2009 \\
\hline $\begin{array}{l}\text { S'lllot } \\
\text { des } \\
\text { Porros }\end{array}$ & SIPHI & 31 & & $\begin{array}{l}\text { Edad de } \\
\text { Hierro }\end{array}$ & $\begin{array}{l}\text { Mallorca, } \\
\text { Islas Bal. }\end{array}$ & Díaz 2009 \\
\hline $\begin{array}{c}\text { Can } \\
\text { Reiners }\end{array}$ & CREM & 28 & 15 & $\begin{array}{l}\text { Edad } \\
\text { Media }\end{array}$ & $\begin{array}{l}\text { Mallorca, } \\
\text { Islas Bal. }\end{array}$ & Díaz 2009 \\
\hline \multicolumn{7}{|l|}{ Mod. } \\
\hline Mallorca & MALL & 112 & 112 & Actual & Islas Bal. & $\begin{array}{l}\text { Picornell } \\
\text { et al. } \\
2005 ; \\
\text { Falchi et } \\
\text { al. } 2006\end{array}$ \\
\hline Menorca & MEN & 46 & 46 & Actual & Islas Bal. & $\begin{array}{l}\text { Picornell } \\
\text { et al. } 2005\end{array}$ \\
\hline Chuetas & $\mathrm{CHU}$ & 47 & 48 & Actual & Islas Bal. & $\begin{array}{l}\text { Picornell } \\
\text { et al. } 2005\end{array}$ \\
\hline Ibiza & IB & 50 & 50 & Actual & Islas Bal. & $\begin{array}{l}\text { Picornell } \\
\text { et al. } 2005\end{array}$ \\
\hline
\end{tabular}

${ }^{1}$ Abreviaturas; ${ }^{2}$ Número de haplogrupos; ${ }^{3}$ Número de secuencias; ${ }^{4}$ Islas Baleares.

Tab. 3. Muestras usadas para la comparación de haplogrupos y haplotipos en las poblaciones (pobl) baleáricas antiguas (ant) y modernas (mod) estudiadas.

\begin{tabular}{|cccc|}
\hline Investigador & $\begin{array}{c}\text { Haplotipo } \\
(16024-16400)\end{array}$ & Haplogrupo & Sexo \\
\hline 1 & rCRS & $\mathrm{H}$ & ऽ \\
\hline 2 & $16104 \mathrm{~T}, 16340 \mathrm{C}$ & $\mathrm{H}$ & † \\
\hline 3 & $16176 \mathrm{~T}$ & $\mathrm{H}$ & + \\
\hline 4 & $16104 \mathrm{~T}, 16362 \mathrm{C}$ & $\mathrm{H}$ & + \\
\hline
\end{tabular}

Tab. 4. Haplogrupo, haplotipo y sexo de los investigadores participantes en el presente estudio.

La necrópolis de Son Olivaret (SOVHI), la otra serie talayótica utilizada, abarca un marco temporal más amplio que la Cova des Pas (CPHI). Es 
un sepulcro colectivo situado en el suroeste de Menorca, en Ciutadella, utilizado posiblemente desde el III milenio a.C. hasta finales del periodo talayótico (Van Strydonck y Boudin 2008). En dicho yacimiento, se distinguen 5 períodos de uso separados por fases de abandono. Se recuperó un gran número de restos humanos tanto del pretalayótico (unidades estratigráficas -UE- 15 y 16) como del talayótico (UE 6 a 11) correspondientes a un mínimo de 160 individuos (Malgosa et al. 2008). Sólo se pudo recuperar material genético del grupo perteneciente al talayótico (Simón y Malgosa 2014). Los restos humanos estaban en mal estado en parte por la naturaleza ácida del suelo y en parte por el colapso de la estructura arquitectónica (Plantalamor et al. 2008).

Las series mallorquinas corresponden a las necrópolis de Son Real (SRHI), S'Illot des Porros (SPHI) y Can Reiners (CREM), todas en la bahía de Alcudia (Fig. 2). La primera está en el centro en una prominencia conocida como el "cementerio de los fenicios" (Hernández-Gasch et al. 1998). Abarca una parte del periodo talayótico tardío (siglos VI al II a.C.) pero continuó en uso (Guerrero et al. 2006a, b), por lo que también es algo más reciente que la Cova des Pas. Posiblemente en sus inicios fuera un cementerio reservado a las clases dominantes a juzgar por los monumentos encontrados, derivando poco a poco hacia un uso más generalizado. Contiene un mínimo de 160 individuos adultos (Font 1977) y 40 subadultos (Alesán y Malgosa 1996). A pesar de que predomina el tipo morfológico grácil mediterráneo, también aparecen tipos craneales del Mediterráneo oriental.

El cementerio de S'Illot des Porros (SPHI) es contemporáneo al de Son Real (siglos VI a II a.C.). Se sitúa en un islote plano de forma elipsoidal a $70 \mathrm{~m}$ de la costa frente a la mencionada necrópolis de Son Real (Tarradell 1964; Hernández-Gasch et al. 1998). Comprende un mínimo de 285 individuos (Alesán et al. 1999). Es destacable que los datos morfológicos muestran un elevado parecido con poblaciones del norte de África o noreste de la Península Ibérica, así como con poblaciones del Mediterráneo oriental (Malgosa 1985). A pesar de ello, los individuos de las necrópolis SRHI y SPHI se relacionan de modo muy estrecho con poblaciones catalanas por sus rasgos craneométricos y dentales (Jordana y Malgosa 2004; García-Sívoli 2009).
Finalmente, la necrópolis de Can Reiners (CREM) es de época tardorromana. Se sitúa sobre el foro de la ciudad romana de Pollentia, una vez abandonado en el siglo III AD (Orfila et al. 1999; Orfila 2000), en una elevación a 14 m por encima del nivel del mar, en el istmo que separa las bahías de Pollença y Alcúdia. Es uno de los yacimientos arqueológicos más importantes de Mallorca (Cau y Chávez 2003) con más de un centenar de individuos (Ortega et al. 2002).

\subsection{Controles de autenticidad}

Uno de los problemas principales del trabajo con ADN antiguo (en adelante $\mathrm{ADNa}$ ) viene dado por la posible contaminación con material genético exógeno. Al estar el material genético tan degradado, cualquier exposición a fuentes mejor conservadas, principalmente ADN actual, incrementan la posibilidad de que éstas últimas sean las observadas en los resultados en lugar del ADN perteneciente a los propios restos arqueológicos. La fuente más probable de contaminación de las muestras es su manipulación por los investigadores bien sean los arqueólogos que las encuentran, bien quienes las tratan en el laboratorio para el estudio de su material genético (Herrmann y Hummel 1994). En concordancia con procedimientos sugeridos anteriormente en trabajos con $\mathrm{ADNa}$ (Cooper et al. 2001; Pääbo et al. 2004; Montiel et al. 2007) las extracciones se llevaron a cabo en un laboratorio aislado, exclusivo para los procesos prePCR. El laboratorio está equipado con presión positiva y un sistema de exposición de luz UV. Además, se utilizó material de un solo uso (guantes estériles, mascarillas, reactivos, pipetas con filtro, etc.), y se lavó con frecuencia con etanol y lejía las superficies de trabajo y del equipo. Finalmente, los investigadores, cuyo perfil genético es conocido, trabajaron siempre primero en el área de prePCR y después en el área de postPCR. Esta medida ha demostrado ser tan efectiva como el uso de las cámaras de presión positiva para evitar contaminaciones (Willerslev y Cooper 2005).

Dos investigadores que presentan haplotipos distintos (Tab. 4, investigadores 1 y 2 ) replicaron totalmente dos de las muestras obtenidas en extracciones independientes. Otras siete pudieron replicarse de forma parcial obteniendo un frag-

Trab. Prehist., 73, N. ${ }^{\circ}$ 2, julio-diciembre 2016, pp. 335-351, ISSN: 0082-5638

doi: $10.3989 /$ tp.2016.12178 
mento de la secuencia y la determinación del haplogrupo mediante RFLPS. Los resultados fueron idénticos en todos los casos. También se clonó la secuencia obtenida en tres de los individuos para verificar que la secuencia directa era el resultado consenso de esa región para dicho individuo, y no el de una molécula afectada por el daño post mortem o el de una molécula exógena no perteneciente al individuo.

Con estas herramientas, y todas las amplificaciones posteriores incluyendo los blancos de extracción y de amplificación, se confirmó la procedencia de las secuencias con una consideración crítica de toda la información disponible. Finalmente, se aplicaron la flexibilidad y el uso inteligente de los criterios de autentificación para una aproximación integrada a las poblaciones humanas (Montiel et al. 2007). Se tuvieron en cuenta las medidas anteriormente mencionadas (normas de esterilización y de separación de laboratorios, uso de blancos de extracción y amplificación, duplicación de muestras, clones, caracterización genética de los investigadores), así como la variabilidad en cada set de extracción, la variabilidad dentro de la muestra global, el sentido filogenético de los resultados y la coincidencia de marcadores relacionados.

\section{RESULTADOS}

Se obtuvieron resultados genéticos en 20 de los 50 individuos analizados, 10 en lo concerniente a la determinación del sexo genético y 20 para ADNmt. De los 10 individuos con sexo determinados con éxito, 6 habían sido diagnosticados ya a nivel morfológico, existiendo una correspondencia clara entre ambos diagnósticos (Tab. 5). Los 4 restantes corresponden a individuos con exigua preservación o de corta edad y escaso dimorfismo sexual, por lo que al no efectuarse el diagnóstico morfológico del sexo, la determinación genética no pudo ser contrastada. Se confirmó así la presencia de 2 individuos masculinos y 1 femenino adultos, así como 4 subadultos masculinos y 3 femeninos.

En relación al ADNmt, se obtuvieron secuencias de la RHVI en un 38\% de las muestras (19 individuos secuenciados a partir de 50 muestras). Se recuperó un fragmento de 231 pb de 17 individuos, mientras que de los individuos \#17 y \#22

\begin{tabular}{|c|c|c|c|c|c|}
\hline Ind. & Edad (años) & $\begin{array}{l}\text { Sexo } \\
\text { morf. }\end{array}$ & Ame. $^{2}$ & SRY & $\begin{array}{l}\text { Determ. } \\
\text { consenso }\end{array}$ \\
\hline 2 & $30-40$ & $\partial$ & $\mathrm{XY}$ & + & $\delta$ \\
\hline 4 & $15-16$ & d? & $X Y$ & + & $\hat{0}$ \\
\hline 9 & $12 \pm 1$ & ㅇ?? & $\mathrm{XX}$ & - & q \\
\hline 25 & $9-10$ & 우? & $\mathrm{XY}$ & + & 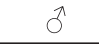 \\
\hline 26 & $13 \pm 1$ & Indet. $^{1}$ & $\mathrm{XX}$ & - & q \\
\hline 37 & $2 \pm 8$ meses & Indet. & $\mathrm{XY}$ & + & $\delta$ \\
\hline 41 & $35-45$ & q & $\mathrm{XX}$ & - & q \\
\hline 50 & $45-50$ & $\delta$ & $\mathrm{XY}$ & + & $\hat{\sigma}$ \\
\hline 57 & $8 \pm 1$ & Indet. & $\mathrm{XX}$ & - & 0 \\
\hline 69 & $12 \pm 1$ & Indet. & $\mathrm{XY}$ & + & q \\
\hline
\end{tabular}

${ }^{1}$ Indeterminado; ${ }^{2}$ Amelogenina.

Tab. 5. Diagnóstico sexual de los individuos inhumados en la Cova des Pas.

sólo fue posible recuperar fragmentos de $150 \mathrm{pb}$ y $129 \mathrm{pb}$ respectivamente.

A nivel de haplogrupos, la eficiencia fue de un $40 \%$, obteniéndose información genética en 20 de los 50 individuos analizados. A los resultados de las secuencias debemos añadir el del individuo \#15, del cual no se pudo recuperar ningún fragmento de la secuencia RHVI, pero al que se pudo analizar por RFLPS. De los 20 individuos, 12 pertenecían al haplogrupo $\mathrm{H}, 5$ al U, 2 al K y 1 al W (Tab. 6, Fig. 3).

De los 11 individuos $\mathrm{H}$ de los que se pudo determinar la secuencia, 9 pertenecían al haplotipo $r C R S$ para el fragmento amplificado (Andrews et al. 1999), mientras que uno presentaba una transición en la posición 16362, y el otro añadía a ésta una transición en la posición 16390. En referencia al haplogrupo U, 3 de $\operatorname{los} 5$ individuos pertenecientes a dicho grupo tenían la secuencia de referencia ( $r C R S)$, mientras que otro presentaba transiciones en las posiciones 16256, 16270,16389 y 16399 , perteneciendo por lo tanto al haplogrupo U5. Finalmente, en un individuo del cual sólo se pudo obtener una secuencia parcial de 129 pb la transición estaba en la posición 16399. La secuencia perteneciente al haplogrupo U5 no es compartida con ningún individuo de las poblaciones actuales ni antiguas de las Baleares; es una secuencia única. Por su parte, los 2 individuos K pertenecían a su haplotipo basal (16224T, 


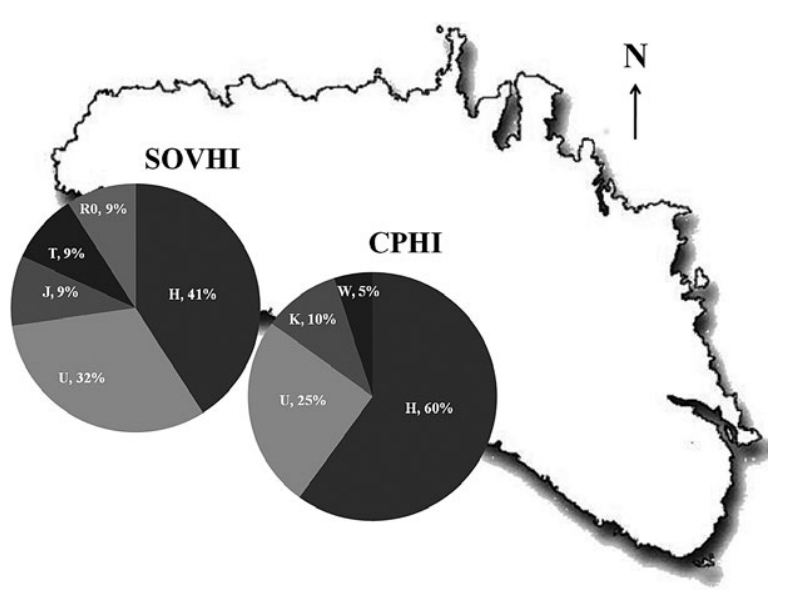

Fig. 3. Distribución de haplogrupos mitocondriales en Cova des Pas (CPHI) y Son Olivaret (SOVHI), las necrópolis talayóticas de Menorca.

16311C), mientras que el individuo determinado con el haplogrupo $\mathrm{W}$ presentaba 2 transiciones, habiendo sufrido una retromutación en una de sus 2 posiciones definitorias, la 16292, que ha sido definida sin embargo como un hotspot mutacional (Santos et al. 2010).

Estos resultados se replicaron en extracciones independientes a fin de autentificarlos: a) se duplicaron totalmente los análisis de los individuos 57 y 62 tanto por secuencia como por restricción, mostrando ambos la secuencia rCRS para el fragmento estudiado. Las duplicaciones fueron llevadas a cabo por 2 investigadores, uno de los cuales presenta una transición en la posición $16340 \mathrm{C}$ en la zona amplificada, que no fue observada en las muestras, con lo que se descarta al primer investigador como origen de una posible contaminación con el haplotipo encontrado con mayor frecuencia; b) se obtuvo por duplicado el fragmento de $150 \mathrm{pb}$ (posiciones 16190 a 16339) en los individuos 2, 4, 11 y 41; c) se duplicó el fragmento de $129 \mathrm{pb}$ (posiciones 16292 a 16420) en el individuo $30, \mathrm{y}$ d) se determinaron por restricción enzimática, también por duplicado, los haplogrupos de los individuos 4, 25, 26, 41 y 47. Además se clonaron tres muestras, obteniendo entre cinco y ocho clones de los individuos 17, 37 y 62 (Tab. 7). En todos los casos se confirmaron los resultados obtenidos previamente.

El análisis de diversidad de Nei considerando los haplogrupos presentes mostró un grado de diversidad genética muy bajo $(0,5947)$ en la po-

\begin{tabular}{|c|c|c|c|c|c|c|c|c|}
\hline Ind & $\begin{array}{c}\text { Sec } \\
(16210- \\
16400) \\
-16000\end{array}$ & $\begin{array}{l}7028 \\
\text { Alu I }\end{array}$ & $\begin{array}{l}12308 \\
\text { Hinf I }\end{array}$ & $\begin{array}{l}11719 \\
\text { Hae II }\end{array}$ & $\begin{array}{c}8994 \\
\text { Hae } \\
\text { III }\end{array}$ & $\begin{array}{c}9052 \\
\text { Hae } \\
\text { II }\end{array}$ & $\begin{array}{c}\mathrm{Hg} \\
\text { RHVI }\end{array}$ & $\begin{array}{c}\mathrm{R} \\
\mathrm{F} \\
\mathrm{PS}\end{array}$ \\
\hline Ind 2 & $362 \mathrm{C}$ & - & - & & & & $\mathrm{H}$ & $\mathrm{H}$ \\
\hline Ind 4 & $r C R S$ & - & + & & & & $\mathrm{U}$ & U \\
\hline Ind 9 & $\begin{array}{l}362 \mathrm{C} \\
390 \mathrm{~A}\end{array}$ & - & & & & & $\mathrm{H}$ & $\mathrm{H}$ \\
\hline Ind 11 & $r C R S$ & & + & & & & U & $\mathrm{U}$ \\
\hline $\begin{array}{l}\text { Ind } \\
15\end{array}$ & n.d & - & & & & & $\mathrm{H}$ & $\mathrm{H}$ \\
\hline Ind 17 & $\begin{array}{c}223 \mathrm{~T}, \\
301 \mathrm{C}\left(1^{\circ}\right)\end{array}$ & + & - & & - & & W & W \\
\hline Ind 22 & $399 \mathrm{G}\left(2^{\circ}\right)$ & + & + & & & & U & $\mathrm{U}$ \\
\hline Ind 25 & $r C R S$ & & & & & & $\mathrm{H}$ & $\mathrm{H}$ \\
\hline Ind 26 & $r C R S$ & - & & & & & $\mathrm{H}$ & $\mathrm{H}$ \\
\hline Ind 29 & $r C R S$ & - & - & $11719 \mathrm{G}$ & & & $\mathrm{H}$ & $\mathrm{H}$ \\
\hline Ind 30 & $r C R S$ & - & & & & & $\mathrm{H}$ & $\mathrm{H}$ \\
\hline Ind 31 & $r C R S$ & - & & & & & $\mathrm{H}$ & $\mathrm{H}$ \\
\hline Ind 35 & $r C R S$ & + & + & & & & U & $\mathrm{U}$ \\
\hline Ind 37 & $\begin{array}{l}256 \mathrm{~T} \\
270 \mathrm{~T} \\
389 \mathrm{~A}, \\
399 \mathrm{G}\end{array}$ & & + & & & & U5 & U5 \\
\hline $\begin{array}{l}\text { Ind } \\
41\end{array}$ & $\begin{array}{l}\text { 224T, } \\
311 \mathrm{C}\end{array}$ & & + & & & - & K & K \\
\hline Ind 47 & $r C R S$ & - & & & & & $\mathrm{H}$ & $\mathrm{H}$ \\
\hline Ind 50 & $\begin{array}{l}224 \mathrm{~T}, \\
311 \mathrm{C}\end{array}$ & + & + & & & - & K & K \\
\hline Ind 57 & $r C R S$ & - & & & & & $\mathrm{H}$ & $\mathrm{H}$ \\
\hline Ind 62 & $r C R S$ & - & & & & & $\mathrm{H}$ & $\mathrm{H}$ \\
\hline Ind 69 & $r C R S$ & & & & & & $\mathrm{H}$ & $\mathrm{H}$ \\
\hline
\end{tabular}

${ }^{1}$ En este caso el resultado se obtuvo secuenciando la zona amplificada y observando la presencia o ausencia de la diana de restricción.

Tab. 6. Caracterización de los individuos (ind) inhumados en la Cova des Pas mediante análisis de polimorfismos de restricción (RFLPS) de la región codificante. $r C R S$ (revised Cambridge Reference Sequence).

blación inhumada en la Cova des Pas: sólo están representados 4 haplogrupos. Esto la sitúa en el nivel más bajo de diversidad de las poblaciones analizadas. En este contexto, el haplogrupo más frecuente es el haplogrupo $\mathrm{H}(60 \%)$ con el porcentaje más alto entre las poblaciones baleares actuales y antiguas, mientras que el haplogrupo $\mathrm{U}$ $(25 \%)$ está en el rango normal de las poblaciones 


\begin{tabular}{|c|c|c|c|c|c|c|c|c|c|c|}
\hline \multirow{2}{*}{ INDIVIDUO } & \multicolumn{10}{|c|}{ Posiciones ADNmt (-16000) } \\
\hline & 210 & 223 & 256 & 270 & 271 & 301 & 322 & 389 & 399 & 401 \\
\hline$r C R S$ & A & $\mathrm{C}$ & $\mathrm{C}$ & $\mathrm{C}$ & $\mathrm{T}$ & $\mathrm{C}$ & A & G & A & $\mathrm{C}$ \\
\hline 17.1 & & $\mathrm{~T}$ & . & . & . & $\mathrm{T}$ & . & & & \\
\hline 17.2 & 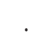 & $\mathrm{T}$ & . & . & . & $\mathrm{T}$ & . & & & \\
\hline 17.3 & . & $\mathrm{T}$ & . & . & . & $\mathrm{T}$ & . & & & \\
\hline 17.4 & . & $\mathrm{T}$ & . & . & $\mathrm{C}$ & $\mathrm{T}$ & . & & & \\
\hline 17.5 & . & $\mathrm{T}$ & . & . & . & $\mathrm{T}$ & . & & & \\
\hline 62.1 & & & . & . & . & . & . & & . & . \\
\hline 62.2 & & & . & . & . & . & . & & . & . \\
\hline 62.3 & . & . & . & . & . & . & . & . & . & . \\
\hline 62.4 & & & . & . & . & . & . & & . & . \\
\hline 62.5 & . & · & . & . & . & . & . & & . & . \\
\hline 62.6 & . & . & . & . & . & . & . & . & . & . \\
\hline 62.7 & . & & . & . & . & . & . & & . & . \\
\hline 62.8 & . & . & . & . & . & . & . & & . & . \\
\hline 37.1 & . & . & $\mathrm{T}$ & $\mathrm{T}$ & . & . & . & . & $\mathrm{G}$ & . \\
\hline 37.2 & & & $\mathrm{~T}$ & $\mathrm{~T}$ & . & . & G & A & $\mathrm{G}$ & . \\
\hline 37.3 & & & $\mathrm{~T}$ & $\mathrm{~T}$ & . & . & . & & & \\
\hline 37.4 & . & & $\mathrm{T}$ & $\mathrm{T}$ & . & . & . & A & $\mathrm{G}$ & . \\
\hline 37.5 & & & $\mathrm{~T}$ & $\mathrm{~T}$ & & . & . & A & $\mathrm{G}$ & . \\
\hline 37.6 & . & . & $\mathrm{T}$ & $\mathrm{T}$ & . & . & . & A & $\mathrm{G}$ & . \\
\hline 37.7 & . & & $\mathrm{T}$ & $\mathrm{T}$ & . & . & . & A & $\mathrm{G}$ & . \\
\hline 37.8 & & & $\mathrm{~T}$ & $\mathrm{~T}$ & . & . & . & A & $\mathrm{G}$ & . \\
\hline
\end{tabular}

Tab. 7. Clones obtenidos de 3 individuos de la Cova des Pas. La revised Cambridge Reference Sequence (rCRS) muestra los nucleótidos situados en las posiciones señaladas en la secuencia de referencia.

comparadas. El tercer haplogrupo en frecuencia, el haplogrupo $\mathrm{K}$, muestra un elevado porcentaje $(10 \%, 2$ individuos), aunque menor que en las poblaciones actuales de Mallorca y Menorca. Por su parte, el único individuo del haplogrupo W (5\%) representa un porcentaje muy similar al hallado en la población menorquina actual $(4,87 \%)$. Dicho haplogrupo no se ha identificado en las comunidades modernas de la isla de Mallorca (Picornell et al. 2005; Falchi et al. 2006) pero sí en las 3 necrópolis mallorquinas antiguas estudiadas (Díaz 2009).

El análisis de correspondencias (Fig. 4) sitúa La Cova des Pas junto a dos de las necrópolis mallorquinas, la población talayótica de S'Illot des Porros y la tardorromana de Can Reiners, debido al alto porcentaje de los dos haplogrupos $\mathrm{H}$ y $\mathrm{U}$ en las tres series (las frecuencias de $\mathrm{H}$ y $\mathrm{U}$ tomadas en conjunto no son inferiores al 85\%). También, las mayores frecuencias del haplogrupo W en las necrópolis antiguas de La Cova des Pas (5\%) y la tardorromana de Can Reiners $(7,14 \%)$ contribuye a su proximidad genética. La Cova des Pas comparte además con Son Olivaret, la otra serie talayótica de Menorca, una elevada frecuencia de los haplogrupos $\mathrm{H}$ y U $(72,71 \%)$, pero Son Olivaret está fuertemente influenciada por la presencia de los haplogrupos J, T y R0 (9,09\% cada uno) ausentes en la serie de estudio. De las series antiguas, la población talayótica mallorquina de Son Real es la más alejada debido a su bajo porcentaje en los haplogrupos H y U $(51,34 \%)$ y a la mayor importancia de haplogrupos poco frecuentes o directamente ausentes en el resto de necrópolis, como puedan ser J $(21,62 \%)$ o $\mathrm{X}(8 \%)$.

La Cova des Pas tampoco muestra una dotación particularmente similar respecto a las poblaciones modernas. En las dos islas mayores, Menorca y Mallorca, actualmente la frecuencia es sensiblemente menor de $\mathrm{H}(26,08 \%$ y $41,07 \%$

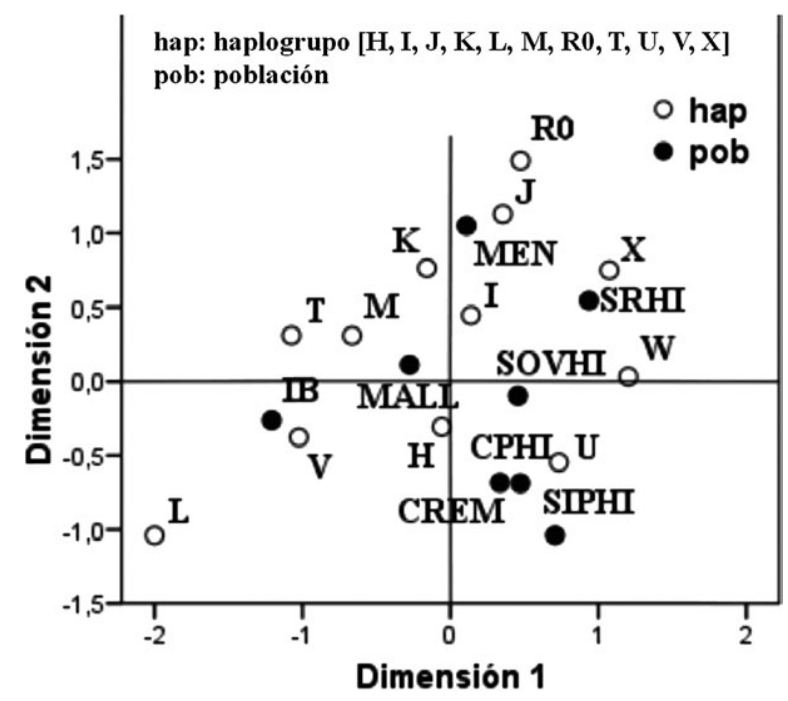

Fig. 4. Análisis de correspondencias de las poblaciones baleares actuales y antiguas: IB Ibiza, MALL Mallorca, MEN Menorca. Cova des Pas (CPHI), Son Olivaret (SOVHI), Son Real (SRHI), S'Illot des Porros (SPHI) y Can Reiners (CREM). 
respectivamente), a la vez que tienen otros haplogrupos como J $(17,39 \%$ vs $8,92 \%)$ que no forman parte de la dotación de la Cova des Pas. Por otra parte, la población de Ibiza también se aleja de Cova des Pas por la alta incidencia de los haplogrupos V (12\%) y T $(26 \%)$ y el hecho de ser la única población balear moderna con un haplogrupo de origen africano (L, 6\%). Ello tiene un gran peso específico en la ubicación lejana de Ibiza tanto respecto a sus contemporáneas como a las series antiguas.

El escalamiento multidimensional de los haplotipos (Fig. 5) muestra la Cova des Pas en el mismo cuadrante que las poblaciones antiguas de Mallorca (SRHI, CREM; no se analizó la necrópolis de S'Illot des Porros por no haberse recuperado secuencias de un tamaño suficiente) y las actuales de Mallorca y Menorca. Estas tienen los haplotipos y frecuencias más habituales en las poblaciones actuales plenamente europeas. En las poblaciones más alejadas se percibe una mayor influencia de poblaciones exteriores, como la africana en Ibiza (Picornell et al. 2005) o del Próximo Oriente en Son Olivaret (Simón y Malgosa 2014). Una mención especial merece la población de Son Real (Díaz 2009) que, a pesar de tener una composición bastante distinta de la Cova des Pas, no queda demasiado apartada de ella en el escalamiento multidimensional. Son Real cuenta con haplotipos de origen no muy bien definido pero atípicos, no encontrados en la actualidad en el continente europeo, y una elevada frecuencia de haplogrupos J y X. Sin embargo, muestra una elevada diversidad haplotípica y en su pool genético aparece la gran

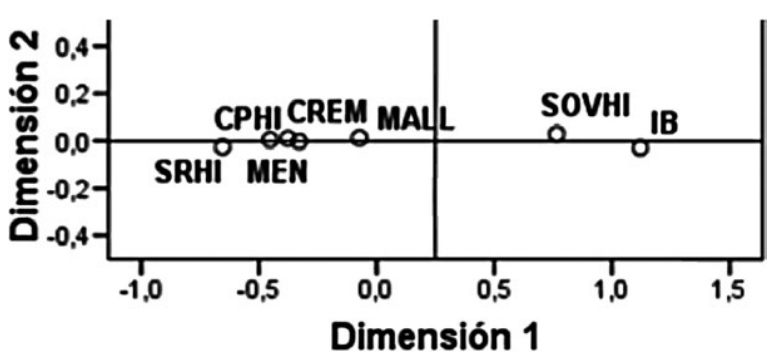

Fig. 5. Escalamiento multidimensional de las poblaciones actuales y antiguas de las Islas Baleares a partir de la secuencia de la primera región hipervariable I del D-loop (RHVI) (región 16210-16365): Son Real (SRHI), Cova des Pas (CPHI), Can Reiners (CREM), MEN Menorca, MALL Mallorca, Son Olivaret (SOVHI), IB Ibiza.

\begin{tabular}{|c|c|c|}
\hline Población & Datación & FST \\
\hline Son Olivaret & Talayótica & $-0,0081$ \\
Can Reiners & Tardoromana & $-0,00807$ \\
Mallorca & Actual & $-0,00776$ \\
Menorca & Actual & $-0,0007$ \\
Son Real & Talayótica & 0,0244 \\
Ibiza & Actual & 0,046 \\
\hline
\end{tabular}

Tab. 8. Distancias genéticas entre la Cova des Pas y el resto de poblaciones baleáricas.

mayoría de los polimorfismos existentes en las poblaciones europeas, compensando así parcialmente su especificidad.

Por último, las distancias genéticas haplotípicas (Tab. 8) con respecto a la Cova des Pas sitúan la población prehistórica menorquina de Son Olivaret, la mallorquina medieval de Can Reiners y las actuales de Menorca y Mallorca con valores negativos. Existen en promedio mayores diferencias entre los individuos de la Cova des Pas que entre los individuos de dicho yacimiento y dichas poblaciones.

\section{DISCUSIÓN}

Los resultados del análisis molecular de 50 individuos del yacimiento talayótico de la Cova des Pas han proporcionado información genética de 20 individuos. Es una eficiencia moderada en la recuperación del ADN con grados de éxito dependientes del protocolo de extracción utilizado (Simón et al. 2012). Estos resultados concuerdan con el bajo grado de conservación bioquímica y molecular de los restos esqueléticos demostrado en los análisis de $\mathrm{C}^{14} \mathrm{e}$ isótopos estables (Van Strydonck et al. 2010), que contrasta con la excelente conservación de los tejidos blandos (Prats-Muñoz et al. 2013). La conservación pasó por cierto grado de sapofinicación, posiblemente responsable de la conservación estructural y la escasa preservación molecular. A pesar de este sesgo en la preservación, los datos obtenidos son claros y coincidentes entre sí. El hecho de que el análisis del ADN mitocondrial, enfocado hacia dos zonas distintas de la molécula, haya dado en todo momento resultados coinciden-

Trab. Prehist., 73, N. ${ }^{\circ}$ 2, julio-diciembre 2016, pp. 335-351, ISSN: 0082-5638

doi: $10.3989 /$ tp.2016.12178 
tes, que haya sucedido lo propio con el análisis de la amelogenina para la determinación sexual en relación al análisis morfológico, la coincidencia en la replicación parcial o total del ADN mitocondrial en extracciones independientes, así como la clonación de tres de los individuos, dan veracidad a la afirmación de que los resultados son robustos y que el ADN obtenido es de origen endógeno. Finalmente, el hecho de que el haplotipo mayoritariamente encontrado $(r C R S)$ se haya obtenido al duplicar 2 individuos en extracciones independientes llevadas a cabo por 2 investigadores con haplotipos distintos (Tab. 4), así como la correspondencia de dicho haplotipo con individuos pertenecientes a 2 haplogrupos distintos ( $\mathrm{H}$ y $\mathrm{U})$ y de ambos sexos (Tabs. 5 y 6) garantizan la ausencia de una contaminación generalizada por parte de uno de los investigadores ( $r C R S$, haplogrupo $\mathrm{H}$, masculino).

Los resultados de la determinación sexual también avalan el estudio morfológico. Se ha identificado el sexo en 4 individuos subadultos y se ha confirmado en otros 3, ampliando la identificación de un 34,8\% (23) de individuos masculinos (Armentano et al. 2010) a $36,4 \%$ (24), de un $36,4 \%$ (24) de individuos femeninos a 40,9\% (27), y disminuyendo el número de indeterminados de 28,8 (19) a $22,7 \%$ (15). La nueva determinación altera ligeramente el porcentaje de sexos, pero continúa habiendo un elevado porcentaje de individuos no diagnosticados a ese nivel. En todo caso, en la necrópolis se constata la presencia de individuos de ambos sexos y distintas edades, confirmando un trato igualitario al menos en el acceso al ritual mortuorio. De todas formas, el ritual funerario es habitualmente un reflejo de la situación y posición social, por lo que se deduce que en esta población talayótica todos los grupos de edad y ambos sexos tenían una consideración similar, siendo considerados integrantes del grupo desde corta edad.

En relación al ADN mitocondrial, los haplogrupos más representados en la necrópolis de la Cova des Pas fueron precisamente los más frecuentes en la mayoría de poblaciones europeas desde el Calcolítico, H y U (Ricaut et al. 2012), como era de esperar. El hecho de que sólo se hayan encontrado 4 haplogrupos $(\mathrm{H}, \mathrm{U}, \mathrm{K}$ y W) refleja una baja diversidad genética $(0,5947)$ y apunta a una alta endogamia, aunque también podría estar influenciada por la baja medida muestral. La composición de haplogrupos en la Cova des Pas no se diferencia significativamente de cualquier otra población balear antigua salvo Son Real, que tiene una baja frecuencia del haplogrupo $\mathrm{H}$ y alta de $\mathrm{J}$ y $\mathrm{X}$ en comparación al resto (Díaz 2009). Lo mismo sucede con la composición de haplotipos, en la que esta necrópolis mallorquina presentó hasta 5 únicos.

A su vez, en la Cova des Pas, la diversidad en la composición haplotípica es baja $(0,5)$ y muy inferior a la de las otras poblaciones baleares antiguas $(0,909$ en la población talayótica mallorquina de Son Real, 0,714 en la menorquina de Son Olivaret y 0,933 en la población tardorromana mallorquina de Can Reiners). Combinando este dato con el elevado porcentaje de haplotipos basales encontrados ( $r C R S$ en los haplogrupos $\mathrm{H}$ y $\mathrm{U}$ y $224 \mathrm{~T}, 311 \mathrm{C}$ en el haplogrupo K), se reafirma la percepción de una cierta identidad grupal con un alto nivel de endogamia. Esta identidad está en consonancia con los patrones funerarios comunes que también se han observado en este enterramiento colectivo sucesivo (Armentano et al. 2010).

En total, se encontraron 4 haplotipos diferentes entre las secuencias con la longitud suficiente para ser incluidas en el análisis estadístico. El haplotipo $r C R S$ está ampliamente representado en las Baleares, tanto en las poblaciones antiguas como en las modernas. En cambio, los haplotipos correspondientes a los dos individuos $\mathrm{H}$ que presentaron mutaciones (\#2 y \#9) no se corresponden con ningún haplotipo reportado en las poblaciones baleares antiguas (Díaz 2009; Simón y Malgosa 2014) pero sí con un individuo actual de Mallorca y otro de Menorca, y con uno de Mallorca respectivamente (Picornell et al. 2005). Estos 2 haplotipos aparecen con una frecuencia moderada en el continente europeo.

A partir de los datos moleculares, se establece un sustrato genético típicamente europeo para la población inhumada en la Cova des Pas. Sin embargo, la comparación con series actuales y antiguas de Menorca y Mallorca muestra la serie de la Cova des Pas como una población bastante más endógama desde el punto de vista de los linajes femeninos, mucho más que cualquiera de las otras necrópolis antiguas $\mathrm{y}$, naturalmente, que las poblaciones que habitan las islas en la actualidad. La baja diversidad, manifestada por los 4 haplogrupos y 5 haplotipos de ADN mitocondrial, sugiere una población de raíces más matriarcales y poca exogamia femenina, en contraste con otra necrópolis talayótica de la isla (Son Olivaret), 
y con las grandes necrópolis mallorquinas (Son Real, S'Illot des Porros y Can Reiners).

Este tipo de comportamiento podría estar relacionado con la idiosincrasia del grupo. Los enterramientos talayóticos en Menorca parecen distribuirse en cuevas alejadas (Cova des Mussol, Cova d'es Càrritx), hipogeos (Torre del Ram), estructuras tipo dolmen (Alcaidús) o sepulcros circulares (Son Olivaret), y finalmente navetas de enterramiento (Rafal Rubí). A veces se buscan espacios alejados de los centros de hábitat, en barrancos y cerca del mar (Javaloyas et al. 2008), caso de cuevas como la Cova des Pas. Estos grupos buscan espacios cerrados, aislados y de muy difícil acceso para sus enterramientos, una forma muy distinta a la ostentosidad de las navetas o estructuras tipo dolmen. Los ritos de los grupos que enterraban en cuevas parecen mucho más elaborados, como demuestran los elementos simbólicos relacionados con tintes del cabello (la Cova des Mussol o Es Càrritx; Lull et al. 1999 a, b), los recipientes complejos de madera y piel para guardar pelo (Cova des Pas, Fullola et al. 2008), o el tratamiento del cuerpo (cadáveres envueltos con pieles y transportados en parihuelas en la Cova des Pas; Armentano et al. 2012 y Prats-Muñoz et al. 2013). Pese a que no se puede descartar la pérdida de evidencias sobre el rito en las zonas más visitadas de las grandes construcciones talayóticas, no se conserva ningún tipo de elementos rituales más allá de la certeza de enterramientos secundarios en algunas navetas (por ejemplo en la Naveta de Rafal Rubí septentrional ${ }^{5}$ ). Así pues, el rito practicado por el pueblo que dio origen a la Cova des Pas denota un comportamiento diferente al de las poblaciones del interior de la isla $\mathrm{y}$, en este caso, la composición genética explica también este comportamiento recluido y aislado. Esta hipótesis es una invitación al estudio genético de nuevos conjuntos de la isla que permitan testar estas inferencias.

\section{AGRADECIMIENTOS}

Este trabajo se enmarca en el proyecto arqueológico de la Cova des Pas y los trabajos del Grupo

5 Véase n. 2. de Recerca en Antropologia Biològica (2014 SGR 1420), reconocido por la Generalitat de Catalunya. Agradecemos a todos los integrantes del equipo de excavación y estudio de la Cova des Pas, y al Consell Insular de Menorca.

\section{BIBLIOGRAFÍA}

Alesán, A. y Malgosa, A. 1996: "Las series subadultas de Son Real y S'Illot des Porros (Periodo Talayótico, Mallorca). Nuevos Datos". Revista Española de Antropología Biológica 17: 37-47.

Alesán, A.; Malgosa, A. y Simó, C. 1999: "Looking into the Demography of an Iron Age Population fromWestern Mediterranean. I. Mortality". American Journal of Physical Anthropology 110: 285-301.

Andrews, R. M.; Kubacka, I.; Chinnery, P. F.; Lightowlers, R. N.; Turnbull, D. M. y Howell, N. 1999: "Reanalysis and revision of the Cambridge reference sequence for human mitochondrial DNA". Nature Genetics 23 (2): 147.

Armentano, N.; Esteve, X.; Nociarová, D. y Malgosa, A. 2012: "Taphonomical study of the anthropological remains from Cova des Pas (Minorca)". Quaternary International 275: 112-119.

Armentano, N.; Jordana, X. y Malgosa, A. 2010: "Aproximación paleodemográfica de una población protohistórica de las Baleares. El yacimiento de la Cova des Pas (Ferreries, Menorca)". Revista de Demografia Histórica XXVIII (I): 91-108.

Arribas, A. 1988: "El megalitisme a les Illes Balears". En La Corona d'Aragó. El misteri de les grans pedres. Aragó. Barcelona-Zaragoza: 102-181.

Bergadà, M. M. y Nicolás, J. C. de 2005: “Aportación de la micromorfología al conocimiento de las prácticas pastoriles de finales de la Edad del Bronce en el yacimiento de la Cova des Morts (Mongofre Nou, Maó, Menorca)". Mayurca 38: 181-202.

Bergadà, M. M.; Poch, R. M. y Cervelló, J. M. 2015: "On the presence of gypsum in the archaeological burial site of Cova des Pas (Menorca, western Mediterranean)". Journal of Archaeological Science 53: 472-481.

Cabanes, D y Albert, M. R. 2011: "Microarchaeology of a collective burial: Cova des Pas (Minorca)". Journal of Archaeological Science 38: 1119-1126.

Calvo, M. y Guerrero, V. 2011: "La cultura talayótica”. En M. Calvo y A. Aguareles (eds.): Calvià, patrimonio cultural. Fundación Calvià. Palma de Mallorca: 89-112.

Cardell, J.; Cau, M. A. y Orfila, M. 1994: "La prehistoria". En G. Alomar, J. Cardell, M.A. Cau y M. Orfila (eds.): Història de Muro I. De la Prehistòria fins al 1229. Ajuntament de Muro. Mallorca: 21-128.

Trab. Prehist., 73, N. ${ }^{\circ}$ 2, julio-diciembre 2016, pp. 335-351, ISSN: 0082-5638

doi: $10.3989 /$ tp.2016.12178 
Cau, M. A. y Chávez, M. E. 2003: "El fenómeno urbano en Mallorca en época romana: los ejemplos de Pollentia y Palma". Mayurqa 29: 27-49.

Cooper, A.; Rambaut, A.; Macaulay, V.; Willerslev, E.; Hansen, A.J. y Stringer, C. 2001: "Human origins and ancient human DNA". Science 292(5522): 1655-56.

Díaz, N. 2009: Bahía de Alcúdia, Mallorca: un crisol genético en el Mediterráneo. Tesis doctoral, Universitat Autònoma de Barcelona. Bellaterra. http:// www.tdx.cat/handle/10803/3712 (consulta 8-I-16).

Excoffier, L.; Laval, G. y Schneider, S. 2005: “ARLEQUIN ver. 3.0: an integrated software package for population genetics data analysis". Evolutionary Bioinformatics Online 1: 47-50.

Falchi, A.; Giovannoni, L.; Calo, C. M.; Piras, I.S.; Moral, P.; Paoli, G.; Vona, G. y Varesi, L. 2006: "Genetic history of some western Mediterranean human isolates through mtDNA HVR1 polymorphisms". Journal of Human Genetics 51(1): 9-14.

Fernández-Miranda, M. y Waldren, W. 1979: "Periodificación cultural y cronología absoluta en la Prehistoria de Mallorca". Trabajos de Prehistoria 36: 349-377.

Font, A. 1977: Estudio de los restos humanos procedentes de la necrópolis de Son Real. Alcudia. Mallorca. Universidad de Barcelona. Barcelona.

Fullola, J. M.; Guerrero, V.; Petit, M. A. P.; Calvo, M.; Malgosa, A.; Armentano, N.; Arnau, P.; Cho, S.; Esteve, X.; Fadrique, T.; Galtés, I.; Garcia, E.; Forés, J.; Jordana, X.; Pedro, M.; Riera, J.; Sintes, E. y Zubillaga, M. 2008: "La Cova des Pas (Ferreries, Menorca): un jaciment cabdal en la prehistòria de les Balears". Unicum, Revista de l'Escola Superior de Conservació i Restauració de Béns Culturals de Catalunya 7: 10-20.

Fullola, J. M.; Petit, M. A. P.; Guerrero, V.; Calvo, M. y Malgosa, A. 2007: "Los hallazgos de la cova des Pas de Ferreries". Revista de Menorca 90: 171-176.

García-Sívoli C. 2009: Estudio diacrónico de los Rasgos Dentales en Poblaciones del Mediterráneo Occidental: Mallorca y Cataluña. Tesis doctoral, Universitat Autònoma de Barcelona. Bellaterra. http:// www.tdx.cat/bitstream/handle/10803/3706/cgs1de1. pdf? sequence=1 (consulta 9-I-16).

Grosjean, R. 1955: "Les statues-menhirs de la Corse I'. Études corses 7-8: 5-36.

Guerrero, V. M.; Calvo, M. y Gornés, S. 2006a: “El poblamiento prehistórico de las Islas Baleares: Desde los orígenes al fin de la Edad del Bronce". En V. M. Guerrero, M. Calvo y S. Gornés (eds.): Historia de las Islas Baleares I. Rey Sol. Palma de Mallorca.

Guerrero, V. M.; Calvo, M. y Gornés, S. 2006b: "Mallorca y Menorca en la Edad del Hierro: la cultura talayótica y postalayótica." En V. M. Guerrero, M. Calvo y S. Gornés (eds.): Historia de las Islas Baleares II. Rey Sol. Palma de Mallorca.
Guerrero, V. M.; Calvo, M. y Salvà, B. 2002: “La Cultura Talayótica. Una sociedad de la Edad del Hierro en la periferia de la colonización fenicia”. Complutum 13: 221-258.

Hernández-Gasch, J.; Sanmartí, J.; Malgosa, A. y Alesán, A. 1998: "La necròpoli talaiòtica de S'Illot des Porros". Pyrenae 29: 69-95.

Herrmann, B. y Hummel, S. 1994: Ancient DNA: Recovery and Analysis of Genetic Material from Paleontological, Archaeological, Museum, Medical, and Forensic Specimens. Springer-Verlag. Berlín.

Izagirre N. 1998: Aplicación de la biología molecular en el estudio antropológico de las poblaciones humanas del pasado: análisis del ADN mitocondrial. Tesis Doctoral, Universidad del País Vasco. Bilbao. http://edtb.euskomedia.org/id/eprint/5666 (consulta 9-I-16).

Javaloyas, D.; Picornell, Ll. y Servera, G. 2008: "Plantas y fenomenología de la muerte durante el Bronce medio y final en Menorca". En Actas de las I Jornadas de Jóvenes en Investigación arqueológica: dialogando con la cultura material (Madrid 2008) I: 207-212. Madrid.

Jordana, X. y Malgosa, A. 2004: "Variabilité morphométrique des populations historiques de la Péninsule Ibérique". Antropo 7: 187-194.

Juan, G. y Plantalamor, L. 1997: Memòria de les excavacions a la naveta de Cala Blanca. 1986-1993. Treballs del Museu de Menorca 21, Conselleria de Cultura, Educació i Esports, Govern de les Illes Balears. Maó.

Kloss-Brandstäetter, A.; Pacher, D.; Schönherr, S.; Weissensteiner, H.; Binna, R.; Specht, G. y Kronenberg, F. 2010: "HaploGrep: a fast and reliable algorithm for automatic classification of mitochondrial DNA haplogroups". Human Mutation 32(1): 25-32.

Kuch, M.; Gröcke, D. R.; Knyf, M. C.; Gilbert, M. T. P.; Younghusband, B.; Young, T.; Marshall, I.; Willerslev, E.; Stoneking, M. y Poinar, H. 2007: "A preliminary analysis of the DNA and diet of the extinct Beothuk: A systematic approach to ancient human DNA". American Journal of Physical Anthropology 132: 594-604.

Lull, V.; Micó, R.; Rihuete, C. y Risch, R. 1999a: La Cova des Mussol un lugar de culto en la Menorca prehistórica. Consell Insular de Menorca, Obra social y Cultural de Sa Nostra. Barcelona.

Lull, V.; Micó, R.; Rihuete, C. y Risch, R. 1999b: Rituales de vida y muerte en la prehistoria de Menorca. La Cova des Càrritx. Consell Insular de Menorca. Obra social y Cultural de Sa Nostra. Barcelona.

Malgosa, A. 1985: Estudi de les restes humanes de la necròpolis talaiòtica de "S'Illot des Porros" Alcúdia-Mallorca. Tesis doctoral, Universitat Autònoma de Barcelona. Bellaterra. http://www.tdx.cat/handle/10803/32171 (consulta 8-I-2016). 
Malgosa, A.; Carrascal, S.; Chimenos, E. y Simón, M. 2008: "Estudi de les restes humanes de Son Olivaret". En L. Plantalamor, S. Villalonga y J. Marquès (eds.): Monument funerari de Son Olivaret. Treballs del Museu de Menorca 30, Conselleria d'Educació i Cultura, Govern de les Illes Balears. Maó: 268-328.

Malgosa, A.; Montiel, R.; Díaz, N.; Solórzano, E.; Smerling, A.; Isidro, A.; García, C. y Simón, M. 2005: "Ancient DNA: a modern look at the infections of the past". En S. G. Pandalai (ed.): Recent research developments in microbiology. Ediciones Trivandrum. India: 213-236.

Mestres, J. S. y Nicolás, J. C. 1999: “Contribución de la datación por radiocarbono al establecimiento de la cronología absoluta de la prehistoria de Menorca". Caesaraugusta 73: 327-341.

Montiel, R. 2001: Estudio diacrónico de la variabilidad del DNA mitocondrial en población catalana. Tesis doctoral, Universitat Autònoma de Barcelona. Bellaterra. http://www.tdx.cat/handle/10803/3641 (consulta 10-I-2016).

Montiel, R.; Francalacci, P. y Malgosa, A. 2007: “Ancient DNA and biological anthropology: believers vs. Skeptics". En C. Santos y M. Lima (eds.): Recent advances in molecular biology and evolution: applications to biological anthropology. Ediciones Trivandrum. India: 209-250.

Montiel, R.; Malgosa, A. y Francalacci, P. 2001: "Authenticating Ancient Human Mitochondrial DNA". Human Biology 73: 689-713.

Nakahori, Y.; Hamano, K.; Iwaya, M. y Nakagome, Y. 1991: "Sex identification by polymerase chain reaction using X-Y homologous primer". American Journal of Medical Genetics 39: 472-473.

Orfila, M. 2000: "El Fòrum de Pollentia. Memòria de les campanyes d'excavacions realitzades entre els anys 1996 i 1999. Ajuntament d'Alcúdia. Àrea de Patrimoni. Alcúdia.

Orfila, M.; Arribas, A. y Cau, M. A. 1999: "La ciudad romana de Pollentia: el foro". Archivo Español de Arqueología 72: 99-118.

Ortega. B.; Chimenos, E. y Malgosa, A. 2002: "Aproximación a la salud oral de los individuos tardo-romanos de Alcudia (Mallorca)". En A. Malgosa, R. M. Nogués y M. P. Aluja (eds.): Antropología y Biodiversidad I. Bellaterra. Barcelona: 386-393.

Pääbo, S., Poinar, H.; Serre, D.; Jaenicke-Després, V.; Hebler, J.; Rohland, N.; Kuch, M.; Krause, J.; Vigilant, L. y Hofreiter, M. 2004: "Genetic analyses from ancient DNA". Annual Review of Genetics 38: 645-679.

Picornell, A.; Gómez-Barbeito, L.; Tomàs, C.; Castro, J. A. y Ramón, M. M. 2005: "Mitochondrial DNA HVRI variation in Balearic populations". American Journal of Physical Anthropology 128: 119-130.

Plantalamor, L.; Villalonga, S. y Marqués, J. 2008: Monument funerari de Son Olivaret. Treballs del Museu de Menorca 30. Maó.
Poinar, H.; Schwarz, C.; Qi, J.; Shapiro, B.; MacPhee, R. D. E.; Buigues, B.; Tikhonov, A.; Huson, D. H.; Tomsho, L. P.; Auch, A.; Rampp, M.; Miller, W. y Schuster, S.C. 2006: "Metagenomics to paleogenomics: Large-scale sequencing of mammoth DNA". Science 311:392-394.

Pons, G. 1999: Anàlisi espacial del poblament al pretalaiòtic final i al talaiòtic I de Mallorca. Col·lecció la Deixa 2, Monografies de Patrimoni Històric, Consell Insular de Mallorca, Cultura i Patrimoni. Palma de Mallorca.

Prats-Muñoz, G.; Galtés, I.; Armentano, N.; Cases, S.; Fernández, P.L. y Malgosa, A. 2013: "Human soft tissue preservation in the Cova des Pas site (Minorca Bronze Age)". Journal of Archaeological Science 40(12): 4701-4710.

Ramakrishnan, U. y Hadly, E. A. 2009: "Using phylochronology to reveal cryptic population histories: review and synthesis of 29 ancient DNA studies". Molecular Ecology 18: 1310- 1330.

Ricaut, F. X.; Cox, M. P.; Lacan, M.; Keyser, C.; Duranthon, F.; Ludes, B.; Guilaine, J. y Crubezy, E. 2012: "A time series of prehistoric mitochondrial DNA reveals Western European genetic diversity was largely established by the Bronze Age". Science Research 2: 14-23.

Richards, M.; Macaulay, V.; Hickey, E.; Vega, E.; Sykes, B.; Guida, V.; Rengo, C.; Sellitto, D.; Cruciani, F.; Kivisild, T.; Villems, R.; Thomas, M.; Rychkov, S.; Rychkov, O.; Rychkov, Y.; Gölge, M.; Dimitrov, D.; Hill, E.; Bradley, D.; Romano, V.; Calì, F.; Vona, G.; Demaine, A.; Papiha, S.; Triantaphyllidis, C.; Stefanescu, G.; Hatina, H.; Belledi, M. M.; Di Rienzo, A.; Novelletto, A.; Oppenheim, A.; Nørby, S.; Al-Zaheri, N.; Santachiara-Benerecetti, S.; Scozari, R.; Torroni, A. y Bandelt, H. J. 2000: "Tracing European founder lineages in the Near Eastern mtDNA pool". Annual of Human Genetics 67: 1251-1276.

Rosselló, G. 1979: La cultura talayótica en Mallorca. Cort. Palma de Mallorca.

Rosselló, G. (ed.) 1987: Les Illes Orientals d'Al-Andalus $i$ les seves relacions amb Sharq Al-Andalus, Magrib i Europa Cristiana (ss. VII-XIII). V Jornades d'Estudis Històrics Locals (1985). Institut d'Estudis Baleàrics. Palma de Mallorca.

Rosselló, G. y Waldren, W. 1973: Excavaciones en el abrigo del bosque de Son Matge (Valldemossa, Mallorca).Ministerio de Educación y Ciencia, Secretaría General Técnica. Madrid.

Salvà, B. 1999: “¿Pueblos del Mar en la cultura Talayótica? Un estado de la cuestión". Gerión 17: 79-104.

Sandars, N. K. 1978: The Sea Peoples. Warriors of the Ancient Mediterranean, 1250-1150 B.C. Thames \& Hudson. London.

Santos, C.; Fregel, R.; Cabrera, V. M.; González, A. M.; Larruga, J. M. y Lima, M. 2010. "Mitochondrial DNA patterns in the Macaronesia islands: Variation

Trab. Prehist., 73, N. ${ }^{\circ}$ 2, julio-diciembre 2016, pp. 335-351, ISSN: 0082-5638

doi: $10.3989 /$ tp.2016.12178 
within and among archipelagos". American Journal of Physical Anthropology 141: 610-619.

Santos, F. R.; Pandya, A. y Tyler-Smith, C. 1998. "Reliability of DNA-based sex tests". Nature Genetics 18: 103.

Schultes, T.; Hummel, S. y Herrmann, B. 2000: “Ancient DNA-typing approaches for the determination of kinship in a disturbed collective burial site". Anthropologisher Anzeiger 58: 37-44.

Schwarz, C.; Debruyne, R.; Kuch, M.; McNally, E.; Schwarcz, H.; Aubrey A. D.; Bada, J. y Poinar, H. 2009: "New insights from old bones: DNA preservation and degradation in permafrost preserved mammoth remains". Nucleic Acids Research 37: 3215-3229.

Simón, M.; González-Ruiz, M.; Prats-Muñoz, G. y Malgosa, A. 2012: "Comparison of two DNA extraction methods in a Spanish Bronze Age burial cave". Quaternary International 247: 358- 362.

Simón, M. y Malgosa, A. 2014: “Caracterització genètica de les restes humanes talaiòtiques del jaciment de Son Olivaret, Ciutadella, Menorca". Revista de Menorca 93: 239-258.

Slatkin, M. 1995: "A measure of population subdivision based on microsatellite allele frequencies". Genetics 139: 457-462.

Solórzano, E. 2006: De la Mesoamérica Prehispánica a la colonial: La huella del DNA antiguo. Tesis doctoral, Universitat Autònoma de Barcelona. Bellaterra. http://www.tdx.cat/handle/10803/3682 (consulta 8-I-2016).

Tarradell, M. 1964: La necrópolis de Son Real y la Illa dels Porros: Mallorca. Excavaciones Arqueológicas en España 24, Ministerio de Educación Nacional. Madrid.
Torroni, A.; Huoponen, K.; Francalacci, P.; Petrozzi, M.; Morelli, L.; Scozzari, R.; Obinu, D.; Savontaus, M. L. y Wallace, D. C. 1996: "Classification of European mtDNAs from an analysis of three European populations". Genetics 144: 1835-1850.

Van Oven, M. y Kayser, M. 2009: "Updated comprehensive phylogenetic tree of global human mitochondrial DNA variation". Human Mutation 30: 386-394.

Van Strydonck, M. y Boudin, M. 2008: "Son Olivaret: les datacions d'un jaciment problemàtic i sorprenent". En L. Plantalamor, S. Villalonga y J. Marquès (eds.): Monument funerari de Son Olivaret. Treballs del Museu de Menorca 30, Conselleria d'Educació i Cultura, Govern de les Illes Balears. Maó: 343-349.

Van Strydonck, M.; Boudin, M.; Guerrero Ayuso, V.; Calvo, M.; Fullola, J. M. y Petit, M. A. 2010: "The necessity of sample quality assessment in 14C AMS dating: The case of Cova des Pas (Menorca - Spain". Nuclear Instruments and Methods in Physics Research Section B: Beam Interactions with Materials and Atoms 268(7-8): 990-994.

Vigilant, L.; Stoneking, M.; Harpending, H.; Hawkes, K. y Wilson, A. C. 1991: "African populations and the evolution of human mitochondrial DNA". Science 253: 1503-1507.

Waldren, W. H. y Van Strydonck, M. 1992: A radiocarbon analysis survey dating the activity sequences of the sanctuary. Prehistoric sanctuary of Son Mas (Valldemossa, Mallorca, Baleares, Spain). Deià Archaeological Museum and Research Centre Series 24. Deià.

Willerslev, E. y Cooper, A. 2005: “Ancient DNA". Proceedings of the Royal Society B: Biological Sciences 272(1558): 3-16. 